\title{
DISCUSSION
}

\section{A new method for single pile settlement prediction and analysis}

\author{
W. G. K. FLEMING (1992). Géotechnique 42, No. 3, 411-425
}

\section{T. J. Poskitt, Queen Mary College, University of London}

The state of stress in the soil surrounding a pile is complex. This is due to the process of installation and subsequent reconsolidation, and also to the stresses which existed in the soil prior to installation, which may not be known. As a result, when the pile is loaded the settlement is difficult to predict, and the level of sophistication which it is sensible to use in theoretical methods must be matched accordingly. The Author recognizes this. The complex problem of single pile settlement is globally characterized by a few parameters related to the hyperbolic law, and these are then found from the load-settlement curve. The numerous cases which the Author has successfully analysed give confidence in the method.

Perhaps the greatest objection to the hyperbolic law is the assumption that, irrespective of soil type or pile make-up a load-settlement curve when plotted on hyperbolic axes (namely settlement/load against settlement) should give a straight line. To define the hyperbola requires two parameters, and it is difficult to see how these relate to the engineering parameters of the pile and soil.

In the Paper this is partially overcome by the use of hyperbolic laws for both the shaft and the base. The four parameters are related to basic soil constants and the method as presented is a significant step forward in the understanding of pile behaviour. However, a consequence of using two hyperbolic relations is that the original assumption that load and settlement conform to a hyperbolic law is now violated. This is readily seen in the case of a rigid pile, given by equation (14), where the graph of $\Delta_{\mathrm{T}} / P_{\mathrm{T}}$ against $\Delta_{\mathrm{T}}$ is no longer linear.

To overcome this problem, the Author suggests that the first part of the curve be associated with shaft parameters, while the second is associated with base parameters. The difficulty with this is knowing where shaft influence ends and base influence takes over. This can be seen in the case study of pile $\mathrm{H}$ at Wembley. Using the data in Fig. 6, and a standard non-linear structural programme, the load-settlement curve for this pile was obtained. This is shown on a hyperbolic plot in Fig. 16. Over the range of loading considered by the Author this gives a gentle curve with no apparent transition from shaft dominance to base dominance. This appears to conflict with the type of behaviour indicated by Fig. 1, and so I suggest that abrupt changes could be due to brittle behaviour in the soil.

The Paper gives persuasive arguments, mainly of a practical kind, for collecting together all the characteristics of shaft behaviour into a single hyperbolic relationship. I believe a better method is to represent shaft behaviour in terms of hyperbolic load transfer functions. This has been done in connection with the related problem of finding the form of dynamic load transfer functions which should be used in pile driving studies. The practical difficulties of taking dynamic measurements initially led me to study static load-settlement curves. Several factors arising from these studies have a direct counterpart in the present Paper.

The first concerns the law used for the basic load transfer function. In pile driving this is generally taken as bilinear (Fig. 17). The Author regards this as an inferior law, but it is necessary to remember that its use is necessitated by the practical need to develop simple numerical procedures for the unloading and reversed loading ranges. The bilinear law, like the hyperbola, requires two parameters to define it, one of which is the ultimate resistance. However, unlike the hyperbola, this is reached after a finite displacement $Q$, which is known as the quake. For the shaft, $Q$ can bc associatcd with $M_{\mathrm{S}} D_{\mathrm{S}}$; for the base its counterpart is $0.6 U_{\mathrm{B}} / E_{\mathrm{B}} D_{\mathrm{B}}$ (see Table 1).

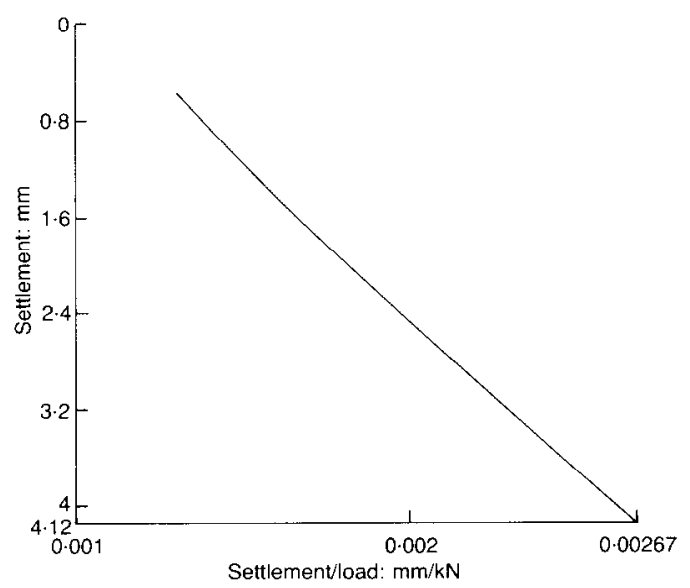

Fig. 16 


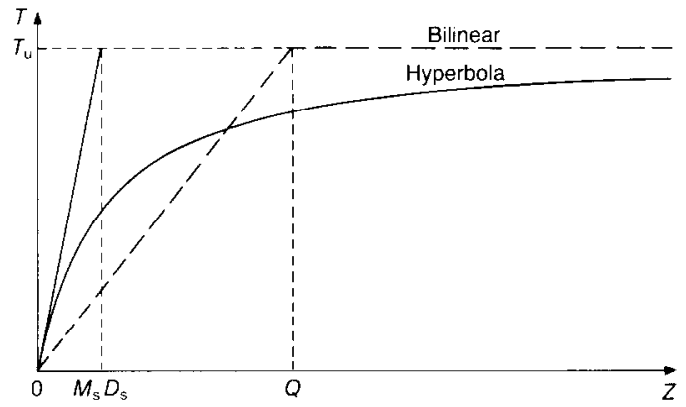

Fig. 17

The Author's comment that $M_{\mathrm{S}}$ does not appear to be sensitive to soil type is significant. This is also found to be the case with quake $Q$, which engineers often assume to be $2.5 \mathrm{~mm}$.

The position with regard to the factor $0.6 U_{\mathrm{B}} / E_{\mathrm{B}} D_{\mathrm{B}}$ is less well defined. Table 1 shows this to be more sensitive than $M_{\mathrm{S}} D_{\mathrm{S}}$ to soil type. I think that this is a consequence of the end resistance continuing to increase with displacement and therefore showing no tendency to approach a horizontal asymptote. This has implications for the values of end quake currently assumed in piledriving analyses.

I should like to comment on the influence of shaft flexibility. The method devised by Poskitt $\&$ Ward (1988) has some similarities with that proposed by the Author, but proved to be illconditioned. As a result, the parameters obtained from back-analysis of field data were found to be sensitive to small changes in the data. From this I concluded that it was necessary to treat the pile and soil as a properly formulated non-linear structural system and solve it accordingly. By comparison, the Author's formulation appears to be well conditioned, and it is not immediately apparent why this should be so. Nevertheless, the efficacy of the method seems beyond doubt and the parameters obtained in the examples are

Table 1. Load test parameters

\begin{tabular}{l|c|c}
\hline \multicolumn{1}{c|}{ Site } & $M_{\mathrm{S}} D_{\mathrm{S}}: \mathrm{mm}$ & $0.6 U_{\mathbf{B}} / E_{\mathbf{B}} D_{\mathbf{B}}: \mathrm{mm}$ \\
\hline Wembley H & 1.32 & 23.4 \\
Wembley N & 0.94 & 21.4 \\
Wembley P & 1.13 & 23.7 \\
Kallo 5 & 0.57 & 6.4 \\
Kallo 2 & 0.32 & 3.2 \\
Norwich 1 & 0.92 & 23.4 \\
Shrewsbury TP1 & 0.90 & 13.6 \\
Shrewsbury TP2 & 0.71 & 9.1 \\
Bristol & 0.42 & 35.5 \\
\hline
\end{tabular}

acceptable whether they are interpreted for load testing or for the less usual application of quake in pile-driving calculations.

\section{Maugeri, F. Castelli and E. Motta, University} of Catania, Italy

To evaluate non-linear single pile settlement, the Author uses the hyperbolic load-transfer function proposed by Chin (1970) which we used to present a computer code based on a pile finite element discretization which takes into account the non-linearity of the soil-pile interaction (Castelli, Maugeri \& Motta, 1992). We also proposed a simplified procedure in a closed form similar to that proposed by the Author.

The computer code was used to back-analyse 12 loading tests of bored piles. Numerical analysis was carried out on instrumental full-scale pile tests, collected from existing literature. The piles were bored in clayey, silty, sandy and pyroclastic soils, ranged between $14 \mathrm{~m}$ and $42 \mathrm{~m}$ long and had diameters ranging between $0.42 \mathrm{~m}$ and $2 \mathrm{~m}$. Assuming a hyperbolic load-transfer function, the back-analysis was performed with the aim of deducing the most appropriate values of the main parameters. The shaft flexibility factor can be evaluated using $M_{\mathrm{S}}=0.001-0.002$ when the unit ultimate skin friction is greater than $50 \mathrm{kPa}$ and $M_{\mathrm{S}}=0.002-0.005$ when the unit ultimate skin friction is less than $50 \mathrm{kPa}$. These values are very close to those given by the Author when applying the Randolph and Wroth theory (1978).

The Author suggests evaluating the contribution of the settlement due to the elastic shortening by three stages $\Delta_{1}, \Delta_{2}$ and $\Delta_{3}$. An alternative procedure could be to assume the soil to be homogeneous and to evaluate the elastic shortening in one stage, considering two laws of soilpile interaction-along the pile shaft and at the base-with different stiffnesses. This gives the second order differential equation

$$
y^{\prime \prime}-\alpha^{2} y=0
$$

where $y$ is the settlement at depth $z$ and $\alpha^{2}$ is given by

$$
\alpha^{2}=4 K_{\mathrm{L}} / E_{\mathrm{c}} \pi D^{2}
$$

where $K_{\mathrm{L}}$ is the stiffness of the lateral loadtransfer function and $D$ is the pile diameter. With the boundary conditions

$$
\begin{aligned}
& E_{\mathrm{c}} \frac{\pi D^{2}}{4} y^{\prime}(0)=-P_{\mathrm{T}} \\
& E_{\mathrm{c}} \frac{\pi D^{2}}{4} y^{\prime}(L)=-\left(P_{\mathrm{T}}-P_{\mathrm{S}}\right)=-K_{\mathrm{p}} y(L)
\end{aligned}
$$


where $K_{\mathrm{p}}$ is the stiffness of the load-transfer function at the base and $L$ is the total length of the pile, the following equation can then be derived for the elastic shortening

$$
\Delta_{\mathrm{e}}=C\left(4 P_{\mathrm{T}} / \alpha E_{\mathrm{c}} \pi D^{2}\right)
$$

where

$$
\begin{aligned}
& C=\frac{\mathrm{e}^{\alpha L}(1+\beta)+\mathrm{e}^{-\alpha L}(1-\beta)-2}{\mathrm{e}^{\alpha L}(1+\beta)-\mathrm{e}^{-\alpha L}(1-\beta)} \\
& \beta=4 K_{\mathrm{P}} / \alpha E_{\mathrm{C}} \pi D^{2}
\end{aligned}
$$

To consider the non-linearity of the loadsettlement curve, the value of $K_{\mathrm{L}}$ must be chosen depending on the load level $\eta$

$$
K_{\mathrm{L}}=K i_{\mathrm{L}}(1-\eta)
$$

where $K i_{\mathrm{L}}$ is the stiffness at the origin and

$$
\eta=P_{\mathbf{T}} /\left(U_{\mathrm{S}}+U_{\mathrm{B}}\right)
$$

Thus this procedure, which takes into account both the shaft and base interactions as well as the load level, also shows the non-linearity of the elastic shortening.

Values of $K i_{\mathrm{L}}$ may be derived as $K i_{\mathrm{L}}-$ $U_{\mathrm{S}} / M_{\mathrm{S}} D$, and the following approximate relationship, deduced from parametric back-analysis, can be used to calculate $K_{\mathrm{P}}$

$$
\left(q_{\mathrm{c}} / K_{\mathrm{p}} D\right)=0.03
$$

where $q_{\mathrm{c}}$ is the point resistance deduced from static penetration testing.

Figures 18 and 19 compare the head settlements evaluated using the Author's procedure with ours for piles $\mathrm{H}$ and $\mathrm{N}$ (Whitaker \& Cooke, 1966). Both procedures were also applied in one of the 12 loading tests (Viggiani \& Vinale, 1983), which was used for the back-analysis, as shown in Fig. 20. All the results show good agreement between measured and computed settlements, irrespective of the procedure used.

For the Viggiani \& Vinale (1983) pile, Fig. 21 shows the elastic shortening $\Delta_{e}$ derived from equations (26)-(31) compared with that derived

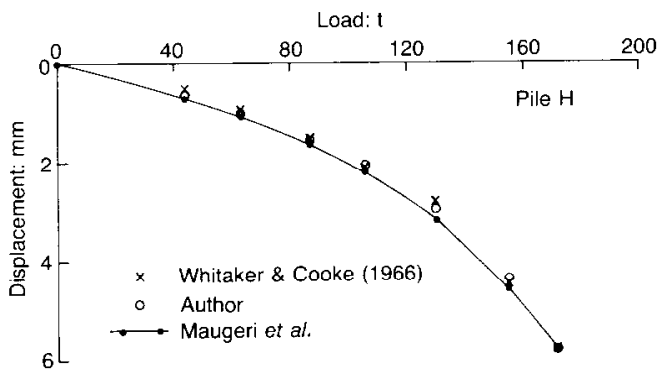

Fig. 18. Evaluation of total settlement for pile $H$

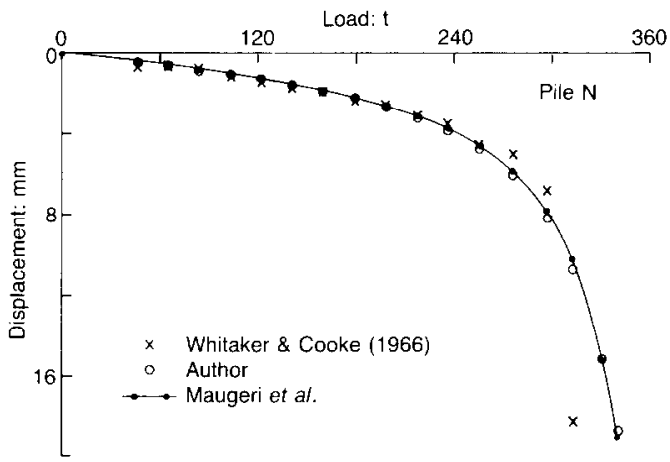

Fig. 19. Evaluation of total settlement for pile $\mathrm{N}$

from equations (17)-(21). Although our procedure predicts a non-linear elastic shortening and the Author's predict a linear one, the results are in good agreement. The main difficulty in applying these methods is in the correct determination of the function parameters. If it is possible therefore for the load-transfer function to be characterized accurately by using a simplified procedure, ana-

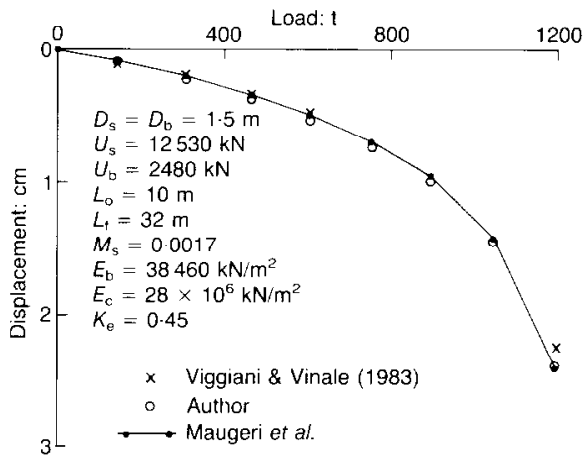

Fig. 20. Evaluation of total settlement for Viggiani \& Vinale (1983) pile

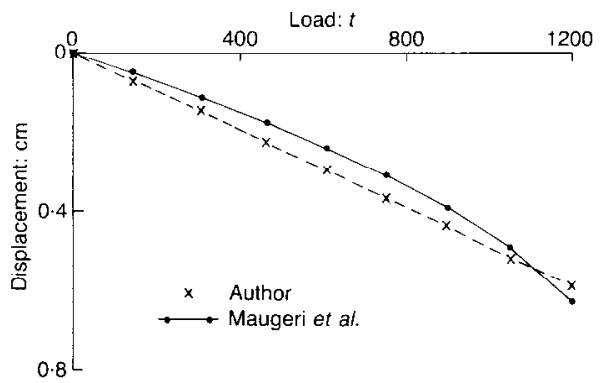

Fig. 21. Evaluation of elastic shortening $\Lambda_{e}$ 
lytical results will show good agreement with fullscale pile tests.

\section{Author's reply}

Since the Paper was written the routine use of the method for the analysis and prediction of single pile settlements and further research on it has been proceeding and the database has been widened to more than 500 case studies without any significant problems having arisen. Research has also been carried out on unloading recovery and it now appears that the maximum value of this can be predicted by a further extension of the same mathematical functions. This also shows how locked in stresses are produced after unloading in a pile. Other developments associated with the method have also been published (Fleming, 1992, 1993; England, 1992).

With regard to the violation of the single hyperbolic relationship when two hyperbolic functions are added for a given deformation, this is indeed inevitable. It is easy to demonstrate mathematically and largely explains the frequent ambivalence of engineers towards the plotting method. Tables 2-4 illustrate the problem. In Table 2 a hyperbolic shaft function characteristic for a rigid pile is shown. A similar characteristic for a pile base alone is shown in Table 3 , and in Table 4 these are mathematically added together

Table 2. Rigid pile with $D_{\mathrm{s}}=1 \mathrm{~m}, U_{\mathrm{s}}=2000 \mathrm{kN}, M_{\mathrm{s}}=0.002$

\begin{tabular}{c|c|c|c}
\hline Applied load: $\mathrm{kN}$ & Settlement: mm & $\begin{array}{c}\text { Settlement/load } \\
\times 10^{3}\end{array}$ & $\begin{array}{c}\text { Interval slope: } \\
\mathrm{kN}\end{array}$ \\
\hline 181.81 & 0.2000 & 1.100 & - \\
400 & 0.5000 & 1.250 & $\begin{array}{c}2000 \\
2000\end{array}$ \\
$620 \cdot 69$ & 0.9000 & 1.450 & - \\
800 & 1.3333 & 1.6667 & - \\
1000 & 2.0000 & 2.000 & - \\
1200 & 3.0000 & 2.500 & 2000 \\
1428.58 & 5.0000 & 3.500 & - \\
1600 & 8.0000 & 5.000 & - \\
1800 & 18.0000 & 10.000 & - \\
\hline
\end{tabular}

Table 3. Rigid pile with $D_{\mathrm{B}}=1 \mathrm{~m}, U_{\mathrm{B}}=1000 \mathrm{kN}, E_{\mathrm{B}}=50000 \mathrm{kN} / \mathrm{m}^{2}\left(E_{25}\right.$ base soil modulus)

\begin{tabular}{c|c|c|c}
\hline Applied load: $\overline{k N}$ & Settlement: mm & $\begin{array}{c}\text { Settlement/load } \\
\times 10^{3}\end{array}$ & $\begin{array}{c}\text { Interval slope: } \\
\mathrm{kN}\end{array}$ \\
\hline 16.39 & 0.2000 & 12.20 & - \\
40 & 0.5000 & 12.50 & 1000 \\
69.77 & 0.9000 & 12.90 & - \\
100 & 1.3333 & 13.33 & - \\
142.86 & 2.0000 & 14.00 & - \\
200 & 3.0000 & 15.00 & - \\
294.12 & 5.0000 & 17.00 & - \\
400 & 8.0000 & 20.00 & - \\
600 & 18.0000 & 30.00 & - \\
\hline
\end{tabular}


Table 4. Rigid pile with $D_{\mathrm{s}}=1 \mathrm{~m}, D_{\mathrm{B}}=1 \mathrm{~m}, U_{\mathrm{s}}=2000 \mathrm{kN}, M_{\mathrm{s}}=0002$, $U_{\mathrm{B}}=1000 \mathrm{kN}, E_{\mathrm{B}}=50000 \mathrm{kN} / \mathrm{m}^{2}$

\begin{tabular}{|c|c|c|c|}
\hline Applied load: $\mathrm{kN}$ & Settlement: $\mathrm{mm}$ & $\begin{array}{l}\text { Settlement/load } \\
\times 10^{3}\end{array}$ & $\begin{array}{c}\text { Interval slope: } \\
\mathrm{kN}\end{array}$ \\
\hline $198 \cdot 2$ & $0 \cdot 2000$ & 1.00908 & $\overline{2356.9}$ \\
\hline 440 & $0 \cdot 5000$ & $1 \cdot 13636$ & $2393 \cdot 5$ \\
\hline $690 \cdot 46$ & $0 \cdot 9000$ & $1 \cdot 303479$ & $2434 \cdot 2$ \\
\hline 900 & $1 \cdot 3333$ & 1.4815 & $\overline{2482} \cdot 9$ \\
\hline $1142 \cdot 86$ & $2 \cdot 0000$ & 1.7500 & $\overline{2545} \cdot 2$ \\
\hline 1400 & 3.0000 & $2 \cdot 1429$ & $\overline{2633 \cdot 3}$ \\
\hline $1722 \cdot 7$ & $5 \cdot 0000$ & $2 \cdot 9024$ & $\overline{2733 \cdot 2}$ \\
\hline 2000 & $8 \cdot 0000$ & $4 \cdot 0000$ & $\overline{2857 \cdot 1}$ \\
\hline 2400 & $18 \cdot 0000$ & 75000 & - \\
\hline
\end{tabular}

for given settlements. The result, considering slope over the selected settlement intervals, clearly shows that the relationship $\Delta_{\mathrm{T}} / P_{\mathrm{T}}$ against $\Delta_{\mathrm{T}}$ is no longer linear. It is undoubtedly true that in order to represent pile behaviour adequately, the functions representing the shaft and base, which are individually hyperbolic, have to be dealt with separately and subsequently combined to represent the whole pile. The method advocated by Chin (1970), for example, works well for piles which have nearly all their load carried either by shaft friction or end bearing, but is disappointing when these components act together and are nearly equal.

On the subject of quake in pile driving, where elastic shortening is restricted to that within the wave front and where volumetric strain along the shaft length is slight, it seems highly probable that quake $Q$ is directly related to $M_{\mathrm{S}} D_{\mathrm{S}}$. Studies on base behaviour under impact seem to show that the stiffness $E_{\mathrm{B}}$ approaches a limiting value of the stiffness of water $\left(E_{\mathrm{B}}=2 \times 10^{6} \mathrm{kN} / \mathrm{m}^{2}\right)$, which might not be entirely unexpected in fully saturated soils.

With regard to the question of the elastic shortening model, at an early stage other forms of analysis using the same basic functions were considered but it was decided to use the method in the Paper because it is straightforward, easily understood, and may be used as an everyday design and analysis tool. The elastic shortening model has since been refined for analysis purposes and the further suggestion of Messrs Maugeri, Castelli and Motta is welcomed. For design purposes, however, the more refined techniques make slight differences and are scarcely necessary, as Figs 18-21 imply. The model used for elastic shortening in the Paper actually produces a bilinear model which changes slope at the point where all shaft friction has been mobilized.

The values for $M_{\mathrm{S}}$ shown in the Paper are now borne out, at least for the stiffer ranges of soil, by a wealth of practical experience.

\section{REFERENCES}

Castelli, F., Maugeri, M. \& Motta, E. (1992). Analisi nonlineare del cedimento di un palo singolo. Riv. Ital. Geotecnica, 26, 115-135.

Chin, F. K. (1970). Estimation of the ultimate load of piles from tests not carried to failure. Proc. 2nd S.E. Asian Conf. Soil Engng, Singapore, 81-92.

Fleming, W. G. K. (1992). Limit states and partial factors in foundation design. Proc. Instn Civ. Engrs Civ. Engng 92, 185-192.

Fleming, W. G. K. (1993). The improvement of pile performance by base grouting. Proc. Instn Civ. Engrs Civ. Engng 97, May, 88-93.

England, M. (1992). Pile settlement behaviour: an accurate model. Application of stress wave theory to piles, pp. 91-96. Rotterdam: Balkema.

Poskitt, T. J. \& Ward, G. (1988). The evaluation of pile load test data in calcareous soils for use in pile driving calculations. Engineering for calcareous sediments, vol. 2, pp. 449-460. Rotterdam: Balkema.

Randolph, M. F. \& Wroth, C. P. (1978). Analysis of deformation of vertically loaded piles. J. Geotech. Engng Div. Am. Soc. Civ. Engrs 104, GT12, 1465.

Whitaker, T. \& Cooke, R. W. (1966). An investigation of the shaft and base resistances of large bored piles in London Clay. Large bored piles, pp. 7-49. London: Institution of Civil Engineers.

Viggiani, C. \& Vinale, F. (1983). Comportamento di pali trivellati di grande diametro in terreni piroclastici. Riv. Ital. Geotecnica, 17, 59-83. 